\title{
UPACARA ADAT PAKANT TALUNT OLEH SUKU DAYAK TUNJUNG DI LERENG GUNUNG ENO
}

\author{
Yulian Widya Saputra ${ }^{1}$, Mei Vita Romadon Ningrum ${ }^{2}$, Rahmadi $^{3}$ \\ 1,2,3 Dosen FKIP Pendidikan Geografi Unversitas Mulawarman \\ e-mail: yulian.widya@fkip.unmul.ac.id
}

\begin{tabular}{|c|c|}
\hline Article Info & Abstract \\
\hline $\begin{array}{l}\text { Keyword: } \\
\text { Pakant Talunt; } \\
\text { Dayak Tunjung; } \\
\text { Mount Eno. }\end{array}$ & $\begin{array}{l}\text { Pakant Talunt is a custom or belief of the Dayak Tunjung community. } \\
\text { In the Dayak language Tunjung feed means to feed and talunt means } \\
\text { forest. Pakant Talunt means to feed the forest. This study aims to } \\
\text { reveal the values and wisdom of the local culture of the Dayak } \\
\text { Tunjung community. This qualitative research uses exploratory } \\
\text { research with an ethnographic approach. Subsequent research analysis } \\
\text { was guided by the ethnographic analysis of Fielding which was } \\
\text { adopted to be simpler with four stages: (1) collecting data, (2) } \\
\text { validating data, (3) analyzing data, (4) interpreting the talunt feed } \\
\text { ceremony by the Dayak Tunjung tribe. The results showed that the } \\
\text { talunt feed ceremony used several offerings in the form of food such } \\
\text { as tara (lemang), tumpiq, free-range chicken, and sagon. This offering } \\
\text { is offered for several things, namely (a) a form of respect for forest } \\
\text { watchmen called penuguq talunt, (b) the Dayak Tunjung community's } \\
\text { efforts to avoid danger when clearing land or visiting tourist } \\
\text { attractions which the Tunjung language calls mogaq talunt, (c) } \\
\text { embodiment of forgiveness to the spirits of the ancestors or referred } \\
\text { to in local language terms with the term tabeq.Thus, the Pakant Talunt } \\
\text { ceremony has a meaning as a form of respect, apology, and prayer to } \\
\text { avoid all the dangers that come from the forest of Mount Eno. }\end{array}$ \\
\hline Article Info & Abstrak \\
\hline $\begin{array}{l}\text { Kata Kunci: } \\
\text { Pakant Talunt; } \\
\text { Dayak Tunjung; } \\
\text { Gunung Eno. }\end{array}$ & $\begin{array}{l}\text { Pakant Talunt adalah adat atau kepercayaan masyarakat Dayak } \\
\text { Tunjung. Dalam bahasa Dayak Tunjung, pakan berarti memberi } \\
\text { makan dan alunt berarti hutan. Pakant Talunt artinya memberi makan } \\
\text { hutan. Penelitian ini bertujuan mengungkap nilai dan kearifan budaya } \\
\text { lokal masyarakat Dayak Tunjung. Penelitian kualitatif ini } \\
\text { menggunakan penelitian eksploratif dengan pendekatan etnografi. } \\
\text { Analisis penelitian selanjutnya berpedoman pada analisis etnografi } \\
\text { Fielding yang diadopsi lebih sederhana dengan empat tahapan: (1) } \\
\text { pengumpulan data, (2) validasi data, (3) analisis data, (4) interpretasi } \\
\text { upacara pemberian makan talun oleh orang Dayak Tunjung. Hasil } \\
\text { penelitian menunjukkan upacara pemberian makan talunt } \\
\text { menggunakan beberapa sesaji berupa makanan seperti tara (lemang), } \\
\text { tumpiq, ayam kampung, dan sagon. Sesajen . ini dipersembahkan } \\
\text { untuk beberapa hal, yaitu (a) bentuk penghormatan terhadap penjaga } \\
\text { hutan yang disebut penuguq talunt, (b) upaya masyarakat Dayak } \\
\text { Tunjung menghindari bahaya saat membuka lahan atau mengunjungi } \\
\text { tempat wisata yang dalam bahasa Tunjung disebut mogaq talunt, (c) } \\
\text { perwujudan pengampunan kepada arwah leluhur atau dalam istilah } \\
\text { bahasa setempat disebut tabeq. Dengan demikian, upacara Pakant } \\
\text { Talunt memiliki makna bentuk penghormatan, permintaan maaf, dan } \\
\text { doa agar terhindar dari segala mara bahaya yang datang dari hutan } \\
\text { Gunung Eno. }\end{array}$ \\
\hline
\end{tabular}




\section{Pendahuluan}

Negara Indonesia di mata dunia internasional diakui menjadi salah satu negara tropis dengan keanekaragaman hayati dan nonhayati yang melimpah. Kekayaan ini terwujudkan dengan kenampakan luasan hutan hujan tropis yang menempati urutan ketiga di dunia. Hal ini sesuai data dan penelitian dari WRI Indonesia (2013) dan Lipu (2010) menyebutkan bahwa separuh hutan tropis terbesar di dunia ada di Indonesia. Hutan tropis Indonesia menempati urutan ketiga setelah Brasil dan Republik Demokrasi Kongo (dulunya Zaire) dan hutan-hutan ini memiliki kekayaan hayati yang unik. Selanjutnya perkembangan hutan hujan tropis ini memiliki peran yang cukup beragam mulai dari berperan dalam perubahan mitigasi iklim, pelestarian budaya, pertumbuhan ekonomi sampai pada kesejahteraan masyarakat disekitar hutan khususnya (Ariyanto, 2014).

Aspek masyarakat dalam pengelolaan hutan ini memiliki peranan penting dalam pelestarian plasma nutfah hutan hujan tropis yang masih alami. Beberapa masyarakat komunal memiliki kearifan dan nilai tersendiri dalam memandang keberadaan hutan hujan tropis ini. Hal ini mengingat penelitian Manuaba (2012) bahwa hutan sebagai aset pembangunan manusia sangat penting dan bermanfaat bagi kehidupan dan penghidupan manusia itu sendiri. Beberapa masyarakat komunal tersebut seperti masyarakat Jawa (suku Jawa), masyarakat Polewali (Suku Mandar), masyarakat Kalimantan (Suku Dayak), masyarakat Lombok dan Bali (suku Lombok dan Bali), serta etnis lain di Indonesia.

Di antara masyarakat komunal di Indonesia tersebut, memandang hutan lebih dari sekadar kumpulan pohon yang hidup. Pandangan tersebut lebih jauh dan meresap ke dalam pola perilaku masyarakatnya yang memiliki ciri masing-masing daerahnya. Hal ini seperti pernyataan dari Soemarwoto (1992) didukung oleh Manuaba (2012), dan Madonna (2019) bahwa secara faktual di setiap provinsi di Indonesia terdapat kesatuan-kesatuan masyarakat hukum adat dengan karakteristiknya masing-masing. Masyarakat hukum adat merupakan kelompok masyarakat yang teratur, menetap di suatu daerah tertentu, bertingkah laku sebagai kesatuan, memiliki penguasa, memiliki hukum adat, memiliki kekayaan sendiri, baik berupa benda yang berwujud ataupun tidak berwujud, dan menguasai sumber daya alam dalam jangkauannya.

Secara khusus penelitian ini mengangkat hal baru, yakni kegiatan pelestarian hutan yang dibalut dalam upacara adat di Pulau Kalimantan oleh masyarakat komunal Suku Dayak. Masyarakat suku Dayak ini di antaranya bermukim selama ratusan tahun di Provinsi Kalimantan Timur (Darmadi, 2016, dan Yusriadi, 2018). Selanjutnya, lokasi penelitian ini berfokus pada Dayak Tunjung di Kabupaten Kutai Barat. Dayak Tunjung merupakan bagian dari suku Dayak yang menempati wilayah Kutai Barat selain Dayak Benuaq, Bahau, dan Aoheng, serta suku Dayak yang lain. Pengambilan Dayak Tunjung ini dibahas untuk mengungkap seluk beluk pelaksanaan salah satu kegiatan adat (upacara) yang dinamakan Pakant Talunt yang ditujukan untuk Hutan di Lereng Gunung Eno.

Upacara Pakant Talunt ini menjadi bagian dari kearifan lokal Dayak Tunjung yang bermukim di Kutai Barat. Kegiatan dilaksanakan di hutan hujan tropis lereng Gunung Eno yang dikeramatkan oleh penduduk Linggang Melapeh. Upacara tersebut pada prinsipnya memiliki sebuah nilai dan kearifan lokal yang unik dan akan diungkap pada artikel penelitian ini. Hal ini sesuai Darmastuti (2012) dan Fitryarini (2014) yang menyatakan bahwa kearifan lokal (local wisdom) adalah ide masyarakat setempat yang memiliki sifat bijaksana, penuh kearifan dan kebaikan yang nilai-nilainya tertanam dan diikuti masyarakatnya.

\section{Metode Penelitian}

Penelitian ini didesain dengan penelitian pendekatan kualitatif. Prayogi dan Daniel (2016:66) didukung oleh Creswell (2012) dan Moleong (2014) merangkum bahwa penelitian kualitatif bersifat natural atau alamiah (apa adanya) tentang perbuatan dan ungkapan kata-kata dari subjek penelitian baik itu perilaku, persepsi, motivasi, dan sebagainya. Perwujudan subjek penelitian ini ditampilkan secara holistik menggunakan deskripsi kata-kata dan bahasa, dalam konteks khusus yang alamiah dengan memanfaatkan bermacam metode alamiah. 
Penelitian kualitatif ini menggunakan jenis penelitian eksplorasi (exploratory research). Ciri dari jenis penelitian eksplorasi ini adalah kajian secara mendalam khususnya tentang perspeksif nilai dan kearifan lokal yang tercermin dalam upacara adat Pakant Talunt yang dilaksanakan di lereng Gunung Eno Linggang Melapeh Kutai Barat. Menurut Ida Bagoes Oka dalam Fitryarini (2014:210) disebutkan bahwa penelitian eksploratif bersifat terbuka dengan penekanan utamanya penemuan akan gagasan maupun pandangan. Penelitian ini selanjutnya lebih jauh mengungkap perspektif nilai dan kearifan budaya lokal Dayak Tunjung yang tercermin pada upacara Pakant Talunt melalui perwujudan beberapa sesajen makanan.

Artikel penelitian kualitatif ini selanjutnya menggunakan pendekatan etnografi. Etnografi itu sendiri dimaknai sebagai deskripsi atau sebuah tafsiran pada wujud budaya atau sistem kelompok sosial-masyarakat. Atkinson \& Hammersley dalam Setyowati (2006:36) menyebutkan etnografi sebagai metode tertua dalam penelitian kualitatif sangat penting bagi penelitian-penelitian sosial yang mempunyai beberapa karakteristik, yaitu (1) menggali atau meneliti fenomena sosial, (2) data tidak terstruktur; (3) kasus atau sampel sedikit; (4) dilakukan analisis data dan interpretasi data tentang arti dari tindakan manusia. Pawito (2008:149) menambahkan pula bahwa etnografi sangat melekat dengan kebudayaan. Kebudayaan bahkan menjadi hal yang pokok dalam studi etnografis. Pendapat lain dari Kamarusdiana (2019:113) menyatakan bahwa dalam implementasinya, etnografi menegaskan pada aspek kebudayaan yang ada. Inilah yang kemudian menjadi ciri penting dari studi etnografi. Dalam penelitian kualitatif etnografi, penelitia melakukan analisis secara mendalam terhadap kebudayaan yang diteliti. Di sisi lain, ada kaitan yang cukup kuat antara etnografi dengan kebudayaan dan masyarakat sebagai hasil kreatifitasnya.

Penelitian kualitatif etnografi ini selanjutnya menggunakan data yang dikumpulkan sepanjang tahun 2019-2021 berupa data primer dan sekunder. Data primer diperoleh dari rekaman observasi dan wawancara pada masyarakat Linggang Melapeh di lereng Gunung Eno yang melakukan upacara Pakant Talunt oleh masyarakat. Data sekunder diperoleh dari studi pustaka terkait sosial budaya suku Dayak Tunjung yang mendiami lereng Gunung Eno. Penentuan lokasi penelitian menggunakan teknik purposive sampling yakni dengan kritetia dimana masyarakat di lereng Gunung Eno tepatnya di Kampung Linggang Melapeh Kutai Barat.

Analisis data tersebut selanjutnya dikaji dengan analisis secara etnografis menurut Langkah analisis pada etnografi menurut Fielding dalam Setyowati (2006:38) meliputi: (1) Mengatur dan mengorganisasi materi-materi yang telah dikumpulkan, (2) membaca kembali data-data tersebut, (3) memilah-milah material kedalam bagian- bagian yang teratur, (4) membangun, membandingkan dan membedakan kategori- kategori. (5) mencari hubungan dan mengelompokan kategori bersama. (6) menemukan dan mendeskripsikan pola, tema dan tipologi. (7) interpretasi dan mencari makna. Selanjutnya, tahapan analisis dari Fielding ini diadopsi menjadi lebih sederhana dengan empat tahapan: (1) mengumpulkan data primer dan sekunder selama tahun 2019-2021 terkait pelaksanaan upacara Pakant Talunt terutama bagian sesajen (makanan), (2) memvalidasi keakuratan hingga menganalisis data yang sudah tervalidasi keakuratan informasinya tentang seluk beluk upacara Pakant Talunt, (4) melakukan penafsiran dari tahap ketiga tersebut dengan kajian pustaka sebagai pembahas dan akhirnya menjadi sebuah informasi makna hingga simpulan tentang upacara Pakant Talunt oleh suku Dayak Tunjung.

\section{Pembahasan}

Pakant Talunt merupakan sebuah adat istiadat atau kepercayaan masyarakat Dayak. Dalam bahasa Dayak Tunjung, Pakant memiliki makna "memberi makan", sedangkan Talunt memiliki makna "hutan". Selanjutnya, istilah Pakant Talunt dimaknai sebagai sebuah kegiatan masyarakat, dalam hal ini masyarakat Dayak Tunjung di lereng Gunung Eno, tepatnya di Kampung Linggang Melapeh Kutai Barat dengan aktivitas pemberian makan (sesaji) pada hutan hujan tropis yang berada di lereng gunung tersebut. Upacara adat Pakant Talunt biasanya dilaksanakan oleh masyarakat Dayak di saat akan adanya pembukaan lahan baru atau keberadaan hutan tua yang sudah lama tidak digunakan oleh 
masyarakat. Secara lanjut upacara adat Pakant Talunt biasanya dilaksanakan pada tempat-tempat wisata yang berada di tengah hutan. Kegiatan ini dapat diketahui sebagai bentuk kepercayaan masyarakat Dayak terutama Tunjung bahwa di setiap tempat wisata atau hutan itu sendiri diyakini memiliki penunggu/penjaga dalam wujud kasat mata (mbaburekso:Jawa) (Adji, 2017 dan Risdianawati et al, 2015).

Kegiatan adat ini menjadi agenda tahunan masyarakat Dayak Tunjung di lereng Gunung Eno. Upacara ini memiliki beberapa tujuan di antaranya; (a) wujud penghormatan terhadap penunggu hutan yang disebut penuguq talunt, (b) usaha masyarakat Dayak Tunjung untuk menghindari mara bahaya saat membuka lahan atau berkunjung ke tempat wisata yang oleh bahasa Tunjung disebut istilah mogaq talunt, (c) perwujudan maaf kepada roh nenek moyang atau dalam istilah bahasa lokal disebut tabeq.

Pelaksanaan upacara Pakant Talunt ini disertai dengan berbagai macam persembahan berupa makanan dan peralatan lain. Secara khusus, persembahan berupa makanan (sesajen: Jawa) ini terdiri dari makanan tradisional yang diolah secara adat. Beberapa makanan yang menjadi ciri upacara Pakant Talunt tersebut antara lain:

\section{Tumpiq}

Tumpiq merupakan makanan yang selalu digunakan dalam setiap upacara adat Dayak. Tumpiq merupakan kue yang terbuat dari tempung kanji yang dicampur dengan tepung beras, gula merah atau gula putih, dan garam. Selain untuk upacara adat, biasanya kue tumpiq juga digunakan dalam acaraacara besar, seperti pernikahan adat Dayak. Tumpiq tersebut seperti pada gambar berikut.

1 (a)



1 (b)

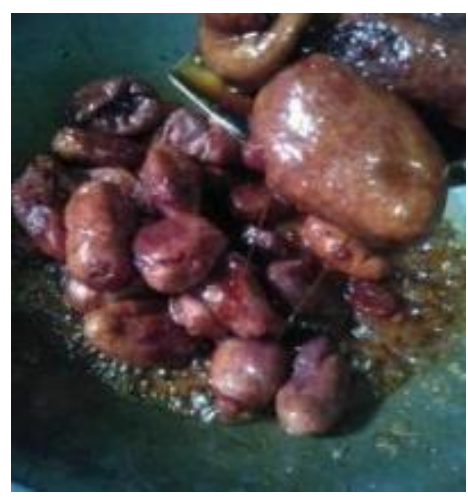

$1(\mathrm{c})$

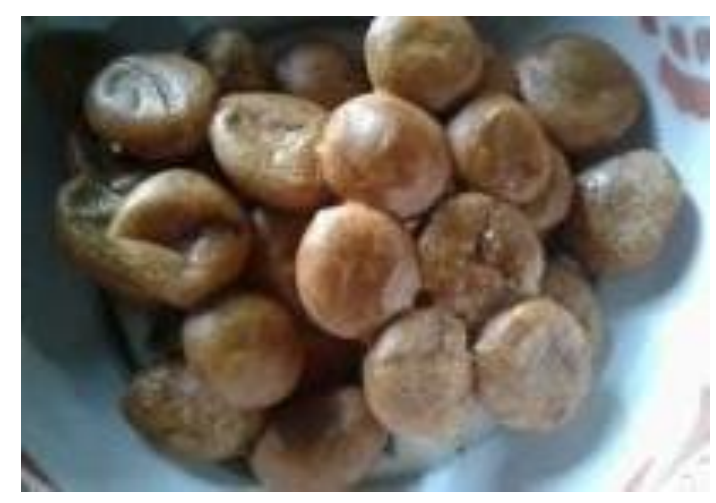

Gambar 1. 1(a) tumpiq dengan bumbu garam dan gula putih, 1 (b) tumpiq dengan bumbu gula putih yang dicairkan, 1 (c) tumpiq yang adonannya dicampur gula merah/aren

(Sumber: Penelitian 2019-2021)

\section{Tara (Lemang)}

Tara merupakan makan yang selalu ada dalam setiap upacara adat yaitu nama lain dari tara adalah lemang seperti pada gambar 2. Biasanya Lemang yang digunakan untuk sesajen yaitu lemang yang dimasak dalam bambu yang kulit luarnya dibersihkan kemudian ujungnya ditutup dengan daun pisang. Bahan pembuatan lemang yaitu beras ketan, santan kelapa, dan bumbu garam. 


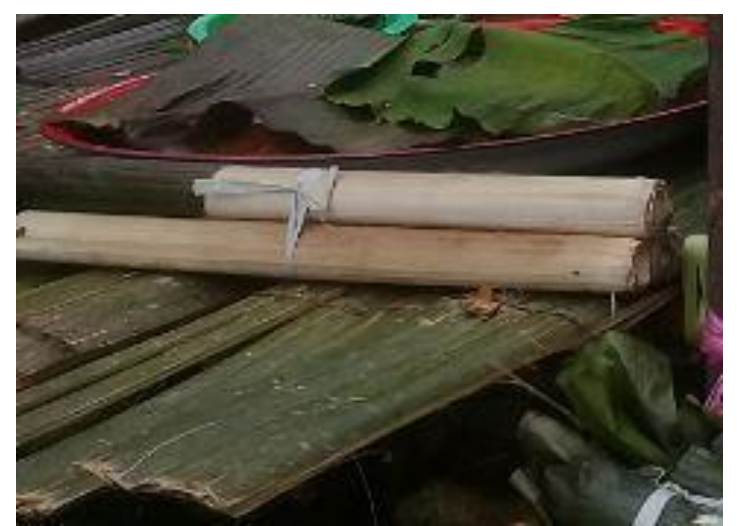

Gambar 2. Tara (Lemang) di upacara Pakant Talunt

(Sumber: Hasil Penelitian 2019-2021)

\section{Ayam Kampung}

Ayam kampung yang digunakan jenis jantan kemudian digunakan untuk sesajen/persembahan dengan disembelih untuk di ambil darah dan dagingnya. Selanjutnya ayamnya dibakar/dipanggang dengan kayu bakar/arang secara utuh dengan dibelah bagian dada sebelah kiri untuk membersihkan isi perutnya.

\section{Sagon}

Sagon merupakan makanan yang juga sering digunakan dalam upacara adat. Adapun bahanbahan sagon yaitu gula pasir, tepung beras dan tambahan kelapa parut. Selain gula pasir biasanya juga bisa dibuat dengan menggunakan bumbu gula aren.

3 (a)

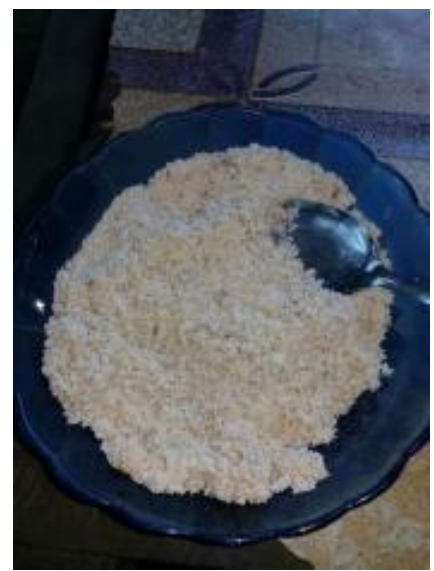

$3(b)$

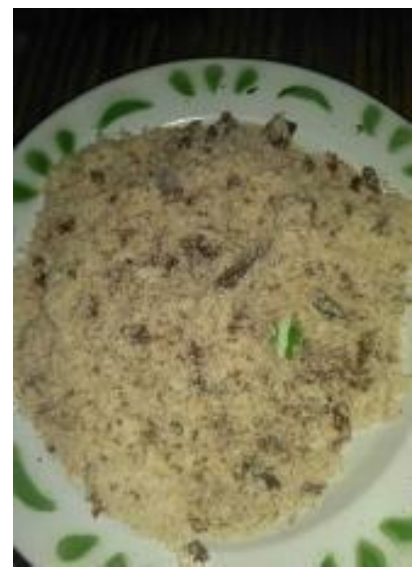

Gambar 3. 3(a) sagon berbumbu gula pasir, 3 (b) sagon berbumbu gula merah/aren (Sumber: Hasil Penelitian 2019-2021)

Penelitian ini selanjutnya dibahas terkait keunikan yang menjadi ciri dari upacara Pakant Talunt. Keunikan tersebut dibahas dengan membandingkan bahan dari sesajen (ubo rampe: Jawa) yang digunakan di dalam upacara tersebut. Pembandingan ini menggunakan adat upacara lain yang mirip sebagai pembanding untuk menemukan persamaan hingga perbedaan nilai serta kearifan lokal yang terdapat dari upacara Pakant Talunt.

Pada upacara Pakant Talunt ini, yang dipersembahkan adalah darah dan ayam jantan yang dibakar. Hal ini sejalan dengan Mariana (2013), yakni sesaji yang bersifat khusus yang digunakan Suku Dayak dalam upacara adat khusus adalah kepala babi, mandau, ayam, darah ayam, jawak, kelekapis, letup padi, dan buah-buahan khas Kalimantan. Lebih lanjut, Adam (2019:25) menguatkan 
bahwa sesajen ayam ini memiliki arti berkelanjutan demi menjaga nilai dan norma masyarakat yang diharapkan oleh leluhur. Dengan adanya sesajen ini, setiap manusia lebih mendekatkan diri kepada Sang Pencipta melalui untaian doa. Identitas ini amat lekat dan menjadi suatu ciri khas oleh masyarakat tradisional.

Penggunaan darah ayam jantan ini bersamaan dengan daging ayam yang diolah sedemikian rupa sebagai perlambang menetralkan energi yang tidak baik. Hal ini diperkuat dari tulisan Kuenna (2015:180), yang menyatakan bahwa darah hewan yang biasa digunakan, yaitu babi, kerbau, dan ayam. Darah hewan ini sebagi lambang hubungan antarmakhluk, antarmanusia, dan fungsinya untuk mendinginkan atau menetralkan. Berbeda dengan Rifai (2019:38), sesajen $i k u n g$ ayam oleh sebagian Suku Jawa dipergunakan untuk makna lain, yakni sebagai perlambang bayi yang baru lahir. Ayam yang biasanya dipanggang/dibakar ini memiliki kemiripan dengan upacara adat Naik Dango oleh Dayak Kanayatn di Kalimantan Barat. Prosesinya setelah mengucapkan doa, ayam tersebut disembelih dan darahnya ditampung untuk melengkapi prosesi upacara Pakant Talunt. Selanjutnya, ayam jantan tersebut dibersihkan lalu dipanggang/direbus dengan bentuk dada ayam terbelah. Perilaku mengolah ayam ini sejalan dengan pernyataan Wina dan Habsari (2017:115) bahwa makna penggunaan sesajen ini disebut ayam selasih sebagai perlambang kemakmuran.

Sesajen berikutnya dalam upacara Pakant Talunt ini, yaitu sagon yang bibuat dari gula pasir, tepung beras, dan kelapa parut. Selain gula pasir, biasanya juga bisa dibuat dengan menggunakan gula aren. Sagon ini sekilas jika dilihat memiliki kemiripan dengan jajan pasar yang ada di upacara adat Jawa, berbahan dasar tepung beras dengan gula merah. Kemiripan nama ini seperti kue sagon yang berasal dari Yogyakarta. Kue tersebut dibuat dari campuran gula merah, tepung beras ditambah parutan kelapa muda yang diadon menjadi bubuk, lalu dibentuk sedemikian rupa. Selanjutnya, kue tersebut dimasak dengan cara dipanggang agar cepat masak. Tampilan sagon ini adonannya juga memiliki kemiripan dengan bahan dasar pembuatan jenang sumsum (bubur), apem, dan kue serabi dalam masyarakat Jawa-Sumatera. Beberapa kue tradisonal tersebut adakalanya melengkapi upacara adat yang memiliki makna sebagai ciri khas komunitas budaya masyarakat. Hal ini sejalan dengan Adam (2019:24), Dewi (2013:118) menyimpulkan bahwa makna semua yang ada di kehidupan ini, terutama kebutuhan sehari-hari masyarakat yang berasal dari alam adalah inti dari asal penciptaan manusia. Oleh karena itu, berbagai hasil alam tersebut, khususnya beras sebagai bahan makanan pokok manusia dan mempunyai banyak manfaat, di samping hasil alam yang lain seperti buah-buahan atau makanan yang sudah diolah menjadi kue atau jajanan pasar patut kita syukuri.

Sesajen selanjutnya adalah tumpiq. Jenis makanan adat tumpiq ini merupakan kue yang terbuat dari tempung kanji yang dicampur dengan tepung beras, gula merah atau gula putih, garam. Selain untuk upacara adat, biasanya kue tumpiq juga digunakan dalam acara-acara adat Dayak Tunjung yang lain. Keberadaan kue tumpiq ini merupakan perlambang kearifan lokal. Kue tumpiq juga dipergunakan oleh masyarakat Dayak Tunjung untuk upacara perkawinan. Yustika (2017:51) menyampaikan keberadaan kue tradisional ini melengkapi ritual ketika mempelai memasuki rumah dilengkapi dengan berbagai macam makanan dan peralatan adat yang lain.

Menurut pandangan Suku Jawa adanya sesajen ini merupakan sebuah simbol pengejawantahan beberapa hal. Adam (2019:24) meyimpulkan bahwa budaya sesajen merupakan salah satu contoh akulturasi budaya antara Hindu-Islam. Sesajen ini menjadi identitas dan akulturasi serta menjaga kearifan lokal seluruh sistem kehidupan. Sesajen merupakan perwujudan unsur spiritual yang melekat di tanah Jawa adalah sesaji yang digunakan untuk persembahan kepada Dzat Ilahi dan juga makhlukmakhluk halus lainnya.

Keberadaan upacara Pakant Talunt ini memiliki keunikan tersendiri pada masyarakat Dayak. Bagi masyarakat Dayak Tunjung, ritual Pakant Talunt ini dipandang sebuah kewajiban bagi komunitasnya. Selain di lereng Gunung Eno ritual Pakant Talunt ini dapat ditemui juga di Kampung Ongko Asa. Pelaksanaan ritual Pakant Talunt tersebut dilaksanakan saat penduduk di kampung tersebut membangun jalan kampung yang melewati hutan. 


\section{Simpulan}

Berdasarkan hasil studi, penelitian dan pembahasan didapatkan kesimpulan bahwa upacara Pakant Talunt yang dilaksanakan di Kampung Linggang Melapeh lereng Gunung Eno memiliki beberapa makna bagi komunitas Dayak Tunjung yang bermukim di kampung Linggang Melapeh. Makna pelaksanaan upacara adat Pakant Talunt ini oleh masyarakat Dayak Tunjung memiliki makna sebagai berikut; (a)wujud penghormatan terhadap penunggu hutan yang disebut penuguq talunt, (b) usaha masyarakat Dayak Tunjung untuk menghindari mara bahaya saat membuka lahan atau berkunjung ke tempat wisata yang oleh bahasa Tunjung disebut istilah mogaq talunt, (c) perwujudan maaf kepada roh nenek moyang atau disebut dengan istilah bahasa lokal dengan dengan istilah tabeq. Dengan demikian upacara adat Pakant Talunt ini bermakna sebagai bentuk penghormatan penunggu hutan (mbaurekso=Jawa), permohonan maaf pada nenek moyang, dan doa untuk menghindari dari segala mara bahaya yang berasal dari hutan Gunung Eno.

\section{Daftar Pustaka}

Ariyanto, dkk. (2014). Kearifan Masyarakat Lokal dalam Pengelolaan Hutan di Desa Rano Kecamatan Balaesang Tanjung Kabupaten Donggala. Jurnal WARTA RIMBA ISSN: 2406$8373 \quad$ Volume $\quad 2, \quad$ Nomor $\quad 2 \quad$ Desember $\quad: 84-91$ http://jurnal.untad.ac.id/jurnal/index.php/WartaRimba/article/download/3618/26 2 diakses 3 Mei 2021

Berianto, A. (2013). Makna Upacara Nyangahatn bagi Masyarakat Desa Pahokng, Kecamatan Mempawah Hulu, Kabupaten Landak, Kalimantan Barat. Skripsi. Universitas Kristen Satya Wacana: Salatiga, (Online) https://repository.uksw.edu/bitstream/123456789/3580/8/T1_152009026_Lampi ran.pdf diakses 13 Mei 2021

Creswell, John.W. (2012). Educatiobal Research Planning, Conducting, and Evaluating Quantitative and Qualitative Research. Edisi keempat. Boston. Pearson Education

Darmastuti, Rini dkk. (2012). Literasi Media dan Kearifan Lokal: Konsep dan Aplikasi. Yogyakarta: Mata Padi Pressindo.

Darmadi, Hamid. (2016). Dayak Asal-usul dan Penyebarannya di Bumi Borneo (1). Jurnal SOSIAL HORIZON: Jurnal Pendidikan Sosial Vol. 3, No. 2. ISSN 2407- 5299 (Online) http://journal.ikippgriptk.ac.id/index.php/sosial/article/downloadSuppFile/376/2 diakses 3 Mei 2021

Dewi, NIMMK. (2013). Kajian Ragam Dan Makna Sesajen Pada Upacara Perang Tipat Bantal Di Desa Kapal Kecamatan Mengwi Kabupaten Badung Provinsi Bali. E- journanl boga. Volume 2, nomor 1, tahun 2013, edisi yudisium periode Februari 2013, hal 118 - 126. https://jurnalmahasiswa.unesa.ac.id/index.php/jurnal-tataboga/article/view/1175/860 diakses 15 Mei 2021

Fitryarini, Inda dkk. (2014). Model Literasi Media Berbasis Kearifan Lokal pada Suku Dayak Tunjung dan Dayak Benuaq di Kutai Barat. Jurnal Ilmu Sosial dan Ilmu Politik Volume 17, Nomor 3, Maret $2014 \quad$ (207-219) ISSN 1410-4946, (online) https://media.neliti.com/media/publications/102293-none-b5df2746.pdf diakses 17 Mei 2021

Kamarusdiana. (2019). Studi Etnografi Dalam Kerangka Masyarakat Dan Budaya. SALAM; Jurnal Sosial \& Budaya Syar-i FSH UIN Syarif Hidayatullah Jakarta Vol. 6 No. 2 (2019), pp.113-128, DOI: $\quad$ 10.15408/sjsbs.v6i2.10975, (online) http://journal.uinjkt.ac.id/index.php/salam/article/view/10975/pdf diakses 17 Mei 2021

Keadaan Hutan Indonesia Bab 1. (2013). Jakarta: WRI Indonesia, (online) https://wriindonesia.org/sites/default/files/keadaan_hutan_bab_1.pdf diakses 17 Mei 2021

Kuenna. (2015). Simbol dalam Upacara Adat Dayak Ngaju (Symbols ini Ritual Tribe of Dayak Ngaju). Jurnal Bahasa, Sastra, dan Pembelajarannya Vol 5, No 2 (2015) hal: 179 187. e-ISSN: 
2580-5932. DOI: 10.20527/jbsp.v5i2.3724 https://media.neliti.com/media/publications/76226ID-none.pdf diakses 17 Mei 2021

Lipu, Sance. (2010). ANALISIS PENGARUH KONVERSI HUTAN TERHADAP LARIAN PERMUKAAN DAN DEBIT SUNGAI BULILI, KABUPATEN

SIGI. Jurnal Media Litbang Sulteng III No. (1) : 44-50 ISSN : 1979-5971,(online) https://media.neliti.com/media/publications/150024-ID-analisis pengaruh- konversihutan-terhada.pdf diakses 17 Mei 2021

Madonna, EA. (2019). Penerapan Hal Masyaraakt Hukum Adat dalam Pengelolaan Hutan di Indonesia. Jurnal Bina Hukum Lingkungan P-ISSN 2541-2353, E-ISSN 2541-531X Volume 3, Nomor 2, April 2019. DOI: 10.24970/jbhl.v3n2.19. (Online) http://bhljurnal.or.id/index.php/bhl/article/view/bhl.v3n2.19 diakses tanggal 3 Mei 2021

Manuaba, IBP et al. (2012). Myth,Indigenous People, and Forest Preservation. Journal ATAVISME, Vol. 15, No. 2, Edisi Desember 2012: 235-245 E-ISSN: 25035215. DOI: 10.24257, (online) https://core.ac.uk/download/pdf/195164458.pdf diakses 15 Mei 2021

Mariana, Elia. (2013). Sesaji dalam Ritual Adat Suku Dayak sebagai Inspirasi Penciptaan Lukisan (Skripsi). Universitas Negeri Yogyakarta: Yogyakarta, (Online) http://eprints.uny.ac.id/20604/1/Elia\%20Mariana\%2008206244027.pdf diakses 12 Mei 2021.

Nafizah, AH. (2018). Nilai Kearifan Lokal dalam Upacara Adat Turun Belang ada Masyarakat Melayu Tamiang (Skripsi). Universitas Sumatera Utara: Medan, (Online) http://repositori.usu.ac.id/bitstream/handle/123456789/11058/140702030.pdf?se quence $=1 \&$ isAllowed=y diakses 13 Mei 2021

Pawito. (2008). Penelitian Komunikasi Kualitatif.Yogyakarta: LKIS.

Prayogi, R. Danial, Endang. (2016). Pergeseran Nilai-Nilai Budaya Pada Suku Bonai Sebagai Civic Culture Di Kecamatan Bonai Darussalam Kabupaten Rokan Hulu Provinsi Riau. Jurnal HUMANIKA Vol. 23 No. 1 (2016) ISSN 1412-941. DOI: 10.14710/humanika.23.1.61-79,

(Online) https://media.neliti.com/media/publications/90595-ID-pergeseran-nilai-nilaibudaya-pada-suku.pdf diakses 14 Mei 2021

Rifai, M. (2019). Etnografi Komunikasi Ritual Tingkeban Neloni dan Mitoni (Studi Etnografi Komunikasi Bagi Etnis Jawa di Desa Sumbersuko Kecamatan Gempol kabupaten Pasuruan). Jurnal of Communication Vol. 2, Nomor. 1, Juni 2017 ISSN 2503-1880, (online) https://core.ac.uk/download/pdf/235573798.pdf diakses 23 Maret 2021

Risdianawati et al. (2015). Sikap Masyarakat terhadap Pelaksanaan Upacara Kelahiran Adat Jawa tahun 2009-2014 (Studi di Desa Bringin Kecaamtan Kauman Kabupaten Ponorogo. JURNAL $\begin{array}{lllllll}\text { AGASTYA } & \text { VOL } & 5 & \text { NO } & 1 & \text { (online) } & \text { http://e- }\end{array}$ journal.unipma.ac.id/index.php/JA/article/download/895/807 diakses tanggal 5 Mei 2021

Setyowati. (2006). Etnografi Sebagai Metode Pilihan Dalam Penelitian Kualitatif di Keperawatan. Jurnal Keperawatan Indonesia, Volume 10, No.1, Maret 2006; 35-45. e-ISSN:2354-9203. doi 10.7454/jki.v10i1.171， (Online) http://jki.ui.ac.id/index.php/jki/article/download/171/339 diakses 15 Mei 2021

Soemarwoto, Otto. (1992). Analisis Dampak Lingkungan. Yogyakarta: UGM Press

Ujang Kusnadi Adam. (2019). Sesajen sebagai Nilai hidup bermasyarakat di Kampung Cipicung Girang Kota Bandung. Indonesian Journal of Sociology, Education ISSN 2685-483X, 1(1), 2 XX. https://media.neliti.com/media/publications/328028-sesajen-sebagai- nilaibermasyaraka-5a7fa91b.pdf diakses 15 Mei 2021

Wina, P dan Habsari. (2017). PERAN PEREMPUAN DAYAK KANAYATN DALAM TRADISI UPACARA NAIK DANGO (STUDI DI DESA PADANG PIO KECAMATAN BANYUKE HULU KABUPATEN LANDAK KALIMANTAN BARAT). JURNAL AGASTYA VOL 7 NO 11 JANUARI 2017. 1 EISSN $25022857, \quad$ (Online) https://core.ac.uk/download/pdf/229500456.pdf diakses 17 Mei 2021 
Yusriadi. (2018). Identitas Dayak dan Melayu di Kalimantan Barat. Jurnal Handep, Vol.1, No. 2, Juni 2018: 1-16. eISSN: 26847256 (Online) https://media.neliti.com/media/publications/292657-identitas-dayak-dan- melayu-dikalimantan-3b7077ba.pdf diakses 3 Mei 2021

Yustika, N. (2017). Menggali simbol-simbol perkawinan adat suku Dayak Tunjung sebagai ungkapan dalam perkawinan Gereja Katolik di Kec. Linggang Bigung, Kab. Kutai Barat, Kalimantan Timur (Skripsi). Universitas Sanatha Darma: Yogyakarta, (online) https://repository.usd.ac.id/9367/ diakses 17 mei 2021 